\title{
The Impact of Search and Recommendation Systems on Sales in Electronic Commerce
}

The Internet and related technologies have vastly expanded the number of products that can be profitably promoted and sold by online retailers. Huge assortments, though, are only beneficial for consumers if search technologies support them in browsing through the huge variety of products. In this paper we illustrate that search technologies can lead to additional consumption and substitution effects depending on the type of search technology applied. For the case of a video-on-demand portal, we can particularly recommend focusing on top lists and search tools since they lead to a considerable amount of additional consumption while recommendation systems lead primarily to substitution. However, retailers can also benefit from substitution if margins in niches are higher than for substituted blockbusters.

DOI 10.1007/s12599-010-0092-x

\section{The Authors}

Juniorprofessor Dr. Oliver Hinz ( $ه)$

E-Finance Lab endowed

Junior-Professorship in E-Finance and

Electronic Markets

Goethe-University Frankfurt

Grüneburgplatz 1

60323 Frankfurt am Main

Germany

ohinz@wiwi.uni-frankfurt.de

Dipl.-Kfm. Jochen Eckert

School of Marketing

Faculty of Business

University of Technology Sydney

City Campus

PO Box 123

Broadway

NSW 2007 Sydney

Australia

jochen.eckert@uts.edu.au

Received: 2009-05-14

Accepted: 2009-09-09

Accepted after one revision

by Prof. Dr. Buhl.

Published online: 2010-03-02

This article is also available in German in print and via http://www. wirtschaftsinformatik.de: Hinz O, Eckert J (2010) Der Einfluss von Such- und Empfehlungssystemen auf den Absatz im Electronic Commerce. WIRTSCHAFTSINFORMATIK. doi: 10.1007/s11576-010-0213-7.
Electronic Supplementary Material The online version of this article (doi: 10.1007/s12599-010-0092-x) contains supplementary material, which is available to authorized users.

(C) Gabler Verlag 2010

\section{Introduction}

The Internet and related technologies have vastly expanded the variety of products that can be profitably stocked, promoted and sold by online retailers (Brynjolfsson et al. 2006, pp. 67-71). In addition, the Internet allows for implementing sales support systems that reduce consumers' search costs. As a result, online retailers offer considerably more products in their assortment than retailers in traditional sales channels. While a typical video rental store offers about 3,000 DVDs (Anderson 2006, p. 23), the online rental store Netflix e.g. currently offers 100,000 titles (Netflix 2009). Consequently, niche products gain importance in online retailing. Thus, Brynjolfsson et al. (2003, pp. 1580-1596) report that books with a sales rank of less than 250,000 on Amazon.com still account for $29.3 \%$ of the total sales. Similar sales distributions can be observed at Netflix and Rhapsody (Anderson 2006, pp. 1-26 and p. 132). This trend toward huge assortments is most evident for information goods, but similar trends can also be observed with regard to physical products, such as fashion goods (see e.g. otto.de).

Huge assortments, however, are only beneficial for consumers if their search for appropriate products is supported by tools which help them to identify products that fit to their preferences. Therefore, search and recommendation tools play a crucial role in e-commerce. In the following we distinguish between sales support systems, which customers can use actively for their search, and recommendation systems that independently recommend products on the basis of certain algorithms and data. We present a detailed classification in Sect. 2.

Search and recommendation systems can have two different consequences for sales: First, decreasing search costs can lead to higher sales based on additional consumption; second, there can also be a shift in demand from blockbusters to niche products and vice versa, so that substitution effects can be observed. These two different consequences (additional consumption and substitution) are of high importance for online retailers: While additional consumption always leads to higher sales and potentially to higher profits, substitution is only advantageous if a lowmargin product is substituted by a product with a higher profit margin. However, if providers know about margin differences between products, sales can systematically be shifted to more profitable products by appropriate search 
and recommendation tools. The basis for such a sales shift, however, is precise knowledge about how various search and recommendation tools affect sales.

Existing literature has particularly analyzed the impact of lower search costs in the Internet on retailer prices (Brynjolfsson et al. 2000; Bakos 1997; Ancarani 2002). Recent studies have also focused on the effects of search technology on the sales distribution between blockbusters and niche products in online markets (Brynjolfsson et al. 2007; Fleder and Hosanagar 2009). However, it has not yet been analyzed to what extent various search and recommendation systems influence sales distribution in different ways nor how they affect total sales.

The aim of this paper is to investigate the influence of different search cost reducing technologies on demand, thereby breaking down the change in sales into additional consumption and substitution. In doing so, the paper illustrates to what extent search and recommendation tools can be used to increase sales. We describe and classify existing search and recommendation systems, empirically analyze their impact on sales and derive recommendations regarding the implementation of search technology for a video-on-demand ( $\mathrm{VoD}$ ) provider.

The paper is structured as follows: First, we describe and classify systems that assist consumers in searching and selecting appropriate products. Subsequently, we illustrate the effect of decreasing search costs on the total sales volume and the distribution of sales across products. In Sect. 4, we examine the impact of various sales support systems on sales of a VoD provider ${ }^{1}$ based on a Hotelling model and by using an agent-based simulation. Here we use real sales and experimental data to calibrate our simulation. In Sect. 5 we summarize our findings and conclude with implications for research and practice.

\section{Reduction of Search Costs Through Sales Support Systems}

Search costs are considered as costs that incur during the search for suitable products. These include explicit costs, e.g. for reaching a store, or implicit costs that incur as a result of the time required for searching the respective item.
Furthermore, opportunity costs emerge. Search costs also include the evaluation effort for a product before buying it: consumers try to determine the quality of products as well as the degree of compliance with their preferences on the basis of available information (Bakos 1997 , p. 1678). Search and recommendation systems aim to reduce these search costs for consumers. It is of importance whether search costs are equally reduced for all products or whether certain products are more favored by the search cost reduction than others. We use the latter distinction to classify search and recommendation systems in Sect. 2.2. In the next section we first provide a literature overview on the impact of search costs.

\subsection{Search Costs}

Bakos (1997, pp. 1676-1692) already discussed the potential of decreasing search costs through the Internet over 10 years ago. The author argues that search costs are much lower online than offline as the competitors are just one click away. Decreasing search costs are essentially seen responsible for improving market efficiency, implying a decreasing profit for the provider at the same time. However, the expectation of an emerging perfect market with one price has not been met (Clay et al. 2002). A possible reason for this is that even online search costs are relatively high, as meanwhile has been frequently documented in literature: Brynjolfsson et al. (2004) show, based on ShopBot data, that the average search costs per product acquisition can be as high as 6.45 USD. Bajari and Hortacsu (2003) calculate the costs of participating in an online auction, consisting of both search costs and costs incurred for mental determination of the bid to be 3.20 USD per bid. A similar study by Hann and Terwiesch (2003) determined that search costs can vary across product categories from 3.54 EUR to 6.08 EUR per bid.

From microeconomics it is well known that search costs can have a significant impact on consumer behavior. Contributions by e.g. Stigler (1961, pp. 213225 ) on the optimal search for information show that consumers search for a longer period if search costs are low and therefore they potentially find other products which better match their preferences. Thus, decreasing search costs can affect the welfare significantly (Wu et al. 2004). Heterogeneous search costs are also one way to pursue price discrimination (Varian 1980; Hinz et al. 2010) as consumers with a higher willingness to pay usually have higher search costs (Tellis 1986, pp. 146-160).

All results show that search costs can have a significant impact on consumer behavior and thus may also affect the market. In general, researchers argue on the grounds of on individual search costs of a consumer (e.g. Varian 1980; Spann et al. 2004). Results by Hann and Terwiesch (2003) indicate, however, that search costs may vary depending on the product. Some products can be found more easily as they are e.g. advertised on the retailer's homepage, while others are hard to find.

The effort of search and consequently the amount of search costs largely depend on the opportunity costs of the seekers and can be reduced by the provider's technology. Therefore, it is not surprising that there can be considerable differences between the providers in terms of search costs. Thus, Ghose and Gu (2007, pp. 16-27) show that search costs vary widely even among online retailers and are significantly lower on Amazon.com than on Barnesandnoble.com. In addition, search costs can explain differences in the sales distribution between online and traditional offline sales channels (Brynjolfsson et al. 2007, pp. 16-27). Brynjolfsson et al. (2007) find evidence that the sales concentration across products is significantly lower in online channels than in traditional sales channels, which means that demand is more evenly distributed across products on offer.

The last two mentioned papers focus on product-specific search costs, while consumer-individual search costs are neglected. We follow this approach. However, our results are independent of this assumption. We consider heterogeneous search costs for products. Therefore, search costs can be considered as product-specific costs that each consumer faces to locate a product.

Sales of a specific product thus essentially represent a function of the consumers' preferences and their chances to find this product. Sales support systems can help consumers by reducing search costs.

${ }^{1}$ The provider does not want to be mentioned. 


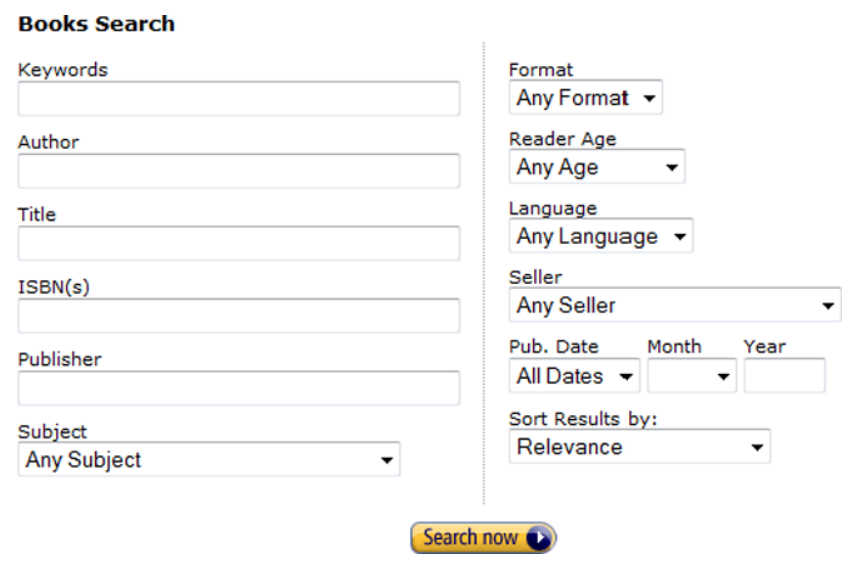

Fig. 1 Typical query form in online stores

Search technologies can be classified into two groups (Brynjolfsson et al. 2006, pp. 69-70): systems in which the consumer actively searches for a product, and systems which independently recommend products to the consumer. In the following we explain the specific functionality, give examples from business practice, and analyze the impact on product-specific search costs.

\subsection{Search Systems}

Search costs are typically much higher in traditional sales channels than in online sales channels because it takes more time to browse shelves in a store in order to obtain an overview of the offered variety of products. In e-commerce, in contrast, the consumer can easily scan huge assortments with the help of search technology. Its simplest form are input text fields (see Fig. 1). There are further developments, such as "Recommendation Agent" and "Comparison Matrix" (see Häubl and Trifts 2000).

It is common to all search systems that they are actively used by the consumer and search costs are generally reduced equally across all products.

\subsection{Recommendation Systems}

Recommendation systems operate on the basis of similarity metrics and determine product recommendations that might be attractive to the specific consumers. These systems analyze the product purchases in order to determine similarities (Ansari et al. 2000, pp. 363375). A distinction is made between the content-based approach, in which products with similar properties are proposed, and collaborative filtering (CF), where similar consumers are searched and recommendations are made based on behavioral patterns. Adomavicius and Tuzhilin (2005, pp. 734-749) present possible realizations of recommendation systems in detail, whereas Resnick and Varian (1997, pp. 56-58) highlight the economic consequences of recommendation systems.

As an example for recommendation systems based on similarities between products we refer to the example of one of the tools used by Amazon that recommends purchasing a bundle of two products. On the basis of CF, purchase decisions are compared across consumers after selecting a product and another product is recommended to the user by the words "Customers who bought this item also bought". Overall, Amazon uses at least seven different recommendation tools (Brynjolfsson et al. 2003, p. 1581).

According to Anderson (2006, pp. 5257 and 122-124) recommendation systems shift demand from blockbusters away toward niches that better match consumer preferences. This result was also confirmed by the study of Fleder and Hosanagar (2009). This effect of recommendation systems can be illustrated by the following example: Suppose that $90 \%$ of all consumers have a preference e.g. for the book "The Stand" by Stephen King, while $10 \%$ of all consumers prefer the book "Lost Symbol" by Dan Brown. If a recommendation system correctly analyses that a consumer belongs to the smaller segment and would prefer the book "Lost Symbol", then the system recommends the book "Lost Symbol" and the consumer will tend to buy this book. In the same situation without such an intelligent system the consumer would, based on probabilities, rather receive the recommendation to buy the book "The Stand" by Stephen King. Recommendation systems, therefore, lead to disproportionately reduced search costs for niches.

\subsection{Hit Lists, Word-of-Mouth, Charts and Unpersonalized Advertising}

However, in online stores also search technology is used that directs the focus of attention towards popular products and recommends blockbusters to the consumer. A familiar example are hit lists (charts) of the most sold products on the online providers' sites, such as music charts. In a similar way, unpersonalized advertising is used, which is generally deployed for products that can expect a large number of consumers. As a consequence, search costs for blockbusters are reduced, further supporting the consumption of blockbusters.

Again this can be illustrated by an example: Suppose two segments, in which $90 \%$ of all consumers in segment 1 have a preference for the book "The Stand" and $10 \%$ of all consumers in segment 2 have a preference for the book "Lost Symbol". If an uninformed consumer from segment 2 meets a consumer from segment 1 who uncritically recommends the book "The Stand" to him, the probability increases that the consumer from segment 2 actually buys this book although he would prefer the book "Lost Symbol". Customer evaluations at Amazon thus also account for this positive feedback loop unless it is clear from the commentary text to which segment the author belongs.

\section{The Influence of Search and Recommendation Tools on Sales and the Sales Distribution of Products}

In the following, we explain the effects of various search and recommendation tools on sales and the sales distribution across products. For both search and recommendation tools we assume a basic scenario in which the corresponding systems are not yet implemented. Then we graphically illustrate the consequences for sales that may result from the introduction of various search and recommendation systems with the help of sales distribution functions. A distinction is made between saturated and unsaturated markets. A market is called saturated if a sales maximum is reached. Companies in saturated markets can only increase sales 
Fig. 2 The influence of search systems on the total sales volume and sales distribution
Additional consumption

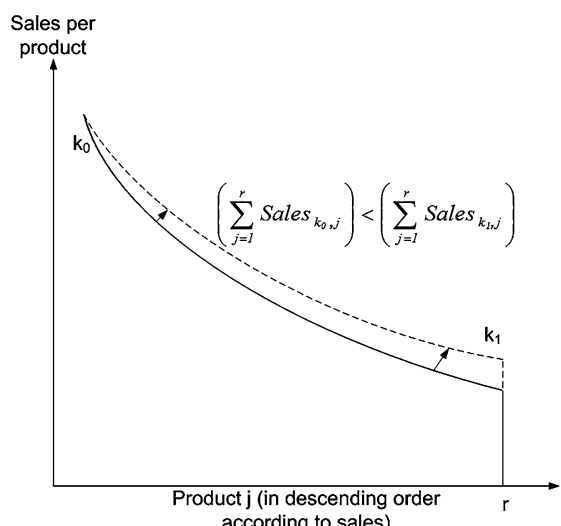

according to sales)
Substitution

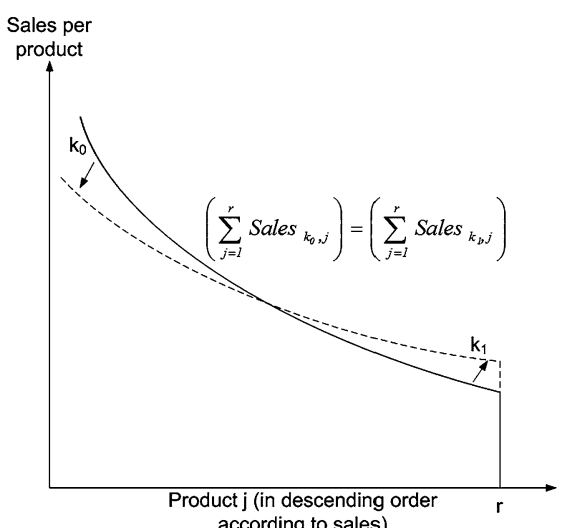

according to sales) through product improvements and thus winning additional market share (Pizam 2005, p. 408). The number of sold products in the market remains constant. In the following we neglect market share shifts. We consider the effects of various search and recommendation systems for the sales of a monopolistic supplier.

Without the ability to additionally acquire sales of other companies, in saturated markets sales changes are based on substitution as consumers cannot extend their sales to additional products as a result of existing consumption restrictions. Consumption restrictions may for example be budget constraints, time constraints, or demand restrictions. The latter is also summarized by Gossen's first law which describes the effect of diminishing marginal returns. The utility of a product decreases with an increased volume of consumption so that even without a budget and/or time restriction a saturation of the individual demand occurs.

In unsaturated markets, on the contrary, changes in sales as a result of search and recommendation tools may also be based on additional consumption, besides substitution. On the one hand, there may be substitution as consumers can now extend their search for suitable products in a cost-effective way. The latter can lead to products being localized that are more consistent with the preferences of the consumer than previously consumed products (Bakos 1997, pp. 1678-1684). The ability of search and recommendation systems to reduce search costs, however, also allows consumers to find, assess, and finally buy additional products (Brynjolfsson et al. 2007 , p. 2), so that additional consumption occurs. In this case, the purchase of (additional) products is not hindered by high search costs. Consumers only search for further purchases if they expect a positive consumer surplus (see also Spann et al. 2004).

In the following we will examine the influence of both search and recommendation systems in two distinct scenarios: On the one hand, we outline changes in sales which are based on $100 \%$ additional consumption; on the other hand, we consider sales changes which are based on $100 \%$ substitution. The latter describes the influence of search and recommendation systems on sales in saturated markets, whereas we assume the occurrence of both effects "additional consumption" and "substitution" in unsaturated markets.

\subsection{Influence of Decreasing Search Costs Due to Search Systems}

Search systems, such as search filters, equally decrease search costs of all products in relative values. Blockbusters are usually easier to find (e.g. due to higher investments in advertising and favorable product placement) and therefore have lower search costs. Consequently, the reduction of search costs for niche products due to search systems amounts to higher absolute values compared to that of blockbusters.

Thus, niches should benefit to a greater extent from the additional consumption in an additional consumption scenario than blockbusters. This scenario is illustrated in the left part of Fig. 2. On the abscissa, the products are plotted in descending order of their sales ranks. On the ordinate, we find the sales per product. The sales distribution function $k_{0}$ illustrates the sales distribution rate before the introduction of a search system, $k_{1}$ the resulting sales distribution after the introduction. The described scenario leads to an increased sales volume for the provider in each case, so that

$\sum_{j=1}^{r}$ Sales $_{k_{0}, j}<\sum_{j=1}^{r}$ Sales $_{k_{1}, j}$

holds, where $r$ is the number of products sold. If only products are sold with a positive margin, the profit of the provider increases.

In the substitution scenario, demand of blockbuster products is shifted towards niches. The reason for this is again that search costs of niche products benefit stronger in absolute terms from a relative search cost reduction. Consumers, who only decided to buy blockbusters as a result of high search costs before the introduction of the search system will now change to niches, if they get a higher consumer surplus with niches. This scenario is illustrated in the right part of Fig. 2. In case of mere substitution, the sales volume remains constant, so that

$\sum_{j=1}^{r}$ Sales $_{k_{0}, j}<\sum_{j=1}^{r}$ Sales $_{k_{1}, j}$

holds. In case of substitution effects the introduction of search systems may even have negative consequences for providers if the profit margin of the substitutes is lower than that of the previously sold products.

In saturated markets, where only substitution effects dominate, providers can only benefit from the introduction of search and recommendation systems if niche products have a higher margin than blockbusters.

In unsaturated markets a profitable introduction of a search system for the supplier is most likely as in addition to 
Fig. 3 The influence of recommendation systems on the total sales volume and sales distribution
Additional consumption

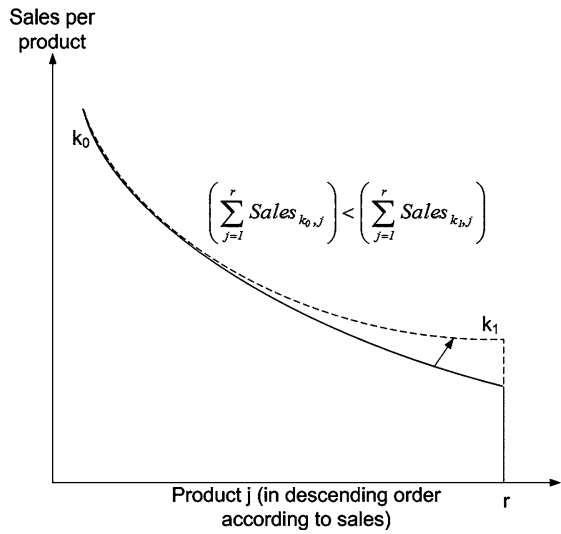

substitution there may also be additional consumption. Even in case of an unfavorable shift in demand from products with higher margins to lower margins, these negative consequences on the amount of sales can be offset by additional consumption. However, whether the introduction of a search system is profitable and if so, to what extent, depends on the extent to which demand changes are based on substitution and/or additional consumption and are dependent on the underlying differences in the products' profit margins.

For consumers, the introduction is beneficial in all cases. They benefit from an increased consumer surplus, either because additional needs can be met by additional consumption or because products are more in accordance with their preferences (substitution).

\subsection{Influence of Decreasing Search Costs Due to Recommendation Systems}

Improved search technology in the form of recommendation systems especially reduce search costs of niche products.

If we assume additional consumption, recommendation systems generate supplementary sales for niches products. Consumers can now achieve a positive consumer surplus with more products in the niches, and thus buy additional products. The left part of Fig. 3 illustrates this scenario.

In the substitution scenario mainly blockbusters, which generally have lower search costs (e.g. through higher investments in advertising and cheaper product placements), are replaced by niche products. Consumers, who prefer niche products but bought blockbusters before the introduction of the recommendation system due to high search cost, can now achieve a higher consumer surplus in the niches. The right part of Fig. 3 illustrates this scenario. The increased sales volume of the niches is at the expense of blockbusters, with the total sales volume remaining constant.

Whether recommendation systems are profitable for the provider again depends on the differences in the products' profit margins and the proportion of additional consumption and substitution. Providers in a saturated market can only benefit if they can achieve a higher margin with niche products. Providers in unsaturated markets should benefit from the introduction of these systems as in addition to substitution also further consumption may occur.

For consumers, the introduction of a recommendation system is beneficial in any case as they can increase their consumer surplus. However, the gain in consumer surplus should be lower than due to an introduction of search systems since primarily search costs of niches and not of all products are reduced.

\subsection{Influence of Decreasing Search Costs Through Hit Lists and Charts}

The use of search technology in terms of hit lists and charts can lead to reduced search costs for blockbusters resulting in an increased sales volume for blockbusters. In this case, the additional sales of blockbusters can have two consequences: If the additional sales volume is not at the expense of other products, we can state pure additional consumption, as shown in the left part of Fig. 4. However, if additional sales are driven by a decline in sales for niches, this means substitution, as illustrated in the right part of Fig. 4.
Substitution

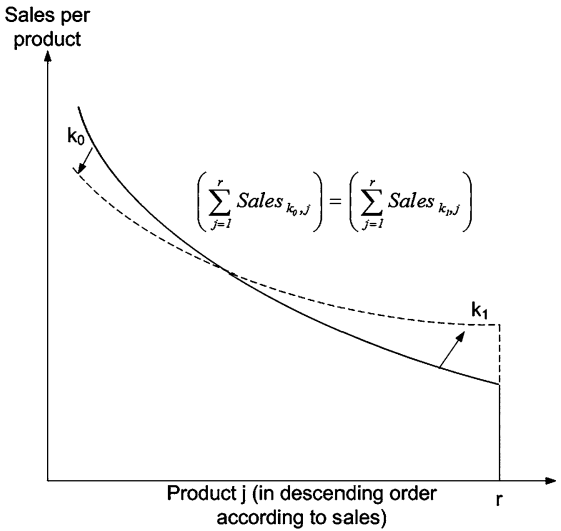

As with the introduction of search and recommendation systems, whether the implementation of hit lists and charts is profitable for the provider again depends on the differences in profit margin in the case of pure substitution for saturated markets and also on the share of additional consumption and substitution for providers in saturated markets.

For consumers, the introduction is advantageous again as the customers' needs are better met resulting in an increased consumer surplus.

Section 3.4 summarizes the results.

\subsection{Overview of the Influence of Search and Recommendation Systems}

Table 1 provides an overview of the extent to which the considered search and recommendation tools influence sales volume, the demand distribution across products as well as consumer and producer surplus.

While search and recommendation systems particularly support the demand in niches, hit lists and charts lead to the opposite effect by promoting sales of blockbusters. Our results also show that the introduction of search and recommendation systems always lead to an increase in consumer surplus independently of substitution and additional consumption. Consumers can either satisfy additional demand with extra niches or blockbusters or switch to products that better match their preferences. Providers facing a saturated market and therefore pure substitution can only benefit from the introduction of search technology if it enables them to shift sales to products with higher profit margins than those of the substituted products. The introduction of search and recommendation systems is more promising in unsaturated 
Fig. 4 The influence of hit lists and charts on their total sales volume and sales distribution
Additional consumption

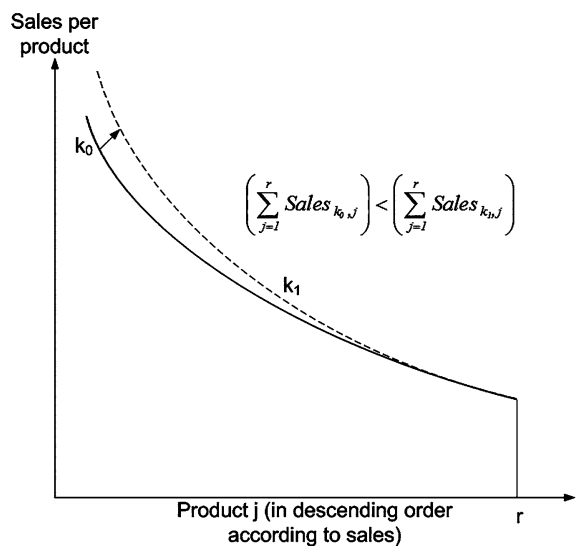

Substitution

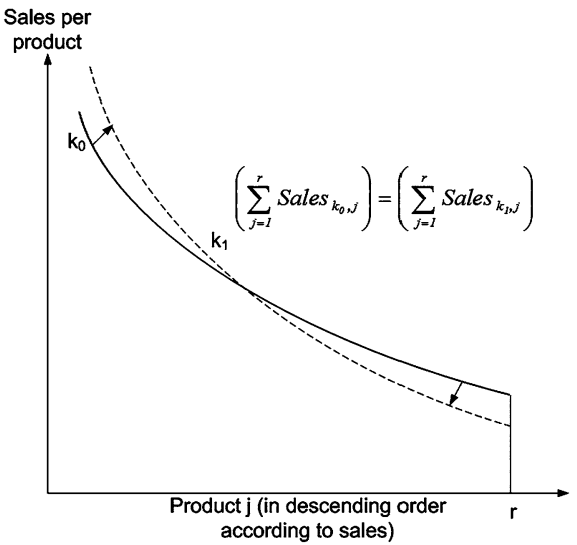

Table 1 Overview of the influence of search and recommendation systems

\begin{tabular}{|c|c|c|c|c|c|}
\hline \multirow[t]{2}{*}{ Scenario } & \multirow[t]{2}{*}{ Target figure } & & \multicolumn{3}{|c|}{ Search technology } \\
\hline & & & Search system & Recommendation system & Hit lists/charts \\
\hline \multirow{4}{*}{$\begin{array}{l}\text { Additional consumption } \\
\text { (unsaturated markets) }\end{array}$} & \multirow[t]{4}{*}{ Sales surplus } & Blockbusters & + & l & + \\
\hline & & Niches & + & + & l \\
\hline & & Consumer & + & + & + \\
\hline & & Producer & $+^{\mathrm{a}}$ & $+^{\mathrm{a}}$ & $+^{\mathrm{a}}$ \\
\hline \multirow{4}{*}{$\begin{array}{l}\text { Substitution } \\
\text { (esp. saturated markets) }\end{array}$} & \multirow[t]{4}{*}{ Sales surplus } & Blockbuster & - & - & + \\
\hline & & Niches & + & + & - \\
\hline & & Consumer & + & + & + \\
\hline & & Producer & $?$ & $?$ & $?$ \\
\hline
\end{tabular}

${ }^{\text {a } O n l y ~ i f ~ p r o d u c t s ~ w i t h ~ a ~ p o s i t i v e ~ p r o f i t ~ m a r g i n ~ a r e ~ s o l d ~}$

markets. In addition to substitution sales changes may also be based on additional consumption in such markets. Assuming that only products with a positive contribution margin are sold, additional consumption always leads to additional profit.

In the next chapter, we first present a microeconomic model that represents consumers' search and purchase behavior. Subsequently, we analyze the influence of different search technologies on sales of a VoD provider by means of an agent-based simulation. In doing so, we illustrate the influence of sales support systems on total sales and the demand distribution across products.

We assume an unsaturated market. This allows us to analyze the potential of search and recommendation systems in terms of a shift in demand with underlying substitution effects, but also to draw conclusions concerning their potential to generate additional consumption. The focus of our study on unsaturated markets is also determined by the available sales data: to calibrate our model we use sales data of a VoD provider. The VoD market, as all markets whose products are primarily aimed at leisure activities of consumers, has to be considered as unsaturated as the consumption can easily be expanded at the expense of alternative leisure activities (Kamakura 2009). Although the latter also constitutes a form of substitution, substitution here occurs across markets and not within one market.

\section{Model and Empirical Analysis}

\subsection{Structure}

In the simulation we assume a monopolistic provider who does not use search and recommendation system in an initial scenario. The provider then implements several search and recommendation tools in further scenarios.

The utility for consumers consists of a deterministic and a stochastic component (Thurstone 1927, pp. 273-286) which reflects the uncertainty about the utility generated by a product before the purchase. After the purchase, the stochastic component of the utility decreases to 0 as the consumer knows its exact value through consumption. This phenomenon occurs specifically in case of information goods and is also known as Arrow's impossibility theorem (Arrow 1962).

The impact of varying search costs on demand is represented with the help of a Hotelling model (Hotelling 1929, pp. 41-57). It is assumed that consumers are equally positioned between 0 and 1 according to their preferences. The horizontally differentiated products on the market are also uniformly distributed between 0 and 1. Fig. 5 illustrates the positioning of products and consumers on the Hotelling line.

The smaller the gap between product and the consumer's position, the more likely the product complies with the consumer's preferences. We use the CityBlock model to calculate the distance (Leunga and Lau 2004, pp. 518-524). Apart 


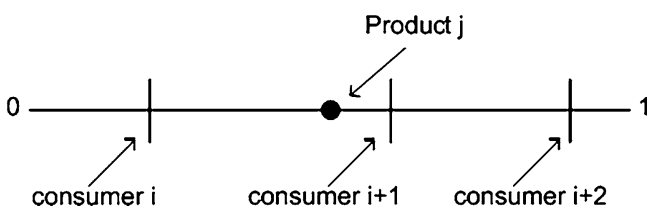

Fig. 5 Consumer and product position for horizontally differentiated products

from the distance between product and consumer, the utility of the product " $j$ " is reduced by its price, which is assumed to be identical for all products. It is also assumed that search costs are homogeneous for all consumers. However, search costs may vary in dependence of the product. This takes into account that niche products involve higher search costs compared to mass market products. It is assumed that consumers have knowledge about the amount of search costs that result from looking for a product.

We consider various purchase occasions. Repeated purchases of the same product by a consumer are not considered. This means, the utility of a product " $j$ " is zero for consumer " $i$ " after the purchase of product " $j$ " by consumer " $i$ ". In order to account for a consumer saturation level, budget constraints, or time constraints, the utility resulting from purchasing the product decreases with the number of previous purchases. It is assumed that the utility decreases linearly with an increasing number of purchases. Formally, a utility function of the following form results:

$$
\begin{aligned}
& u_{i, j, t}=\left(a \cdot(1+z)-p-s_{j}-\left|k_{i}-q_{j}\right|\right. \\
&\left.-f\left(n_{i, T}\right)\right) \cdot x_{i, j, T} \\
&(i \in I, j \in J, t \in T)
\end{aligned}
$$

with: $u_{i, j, t}$ : utility of product $j$ for consumer $i$ in purchase occasion $t$; $a$ : utility constant; $z$ : stochastic component of utility, where $z \sim[0 ; 0.1] ; s_{j}$ : search cost parameter of product $j$, where $s_{j} \sim 1-$ $\mathrm{NV}(\mu, \sigma) \cdot d+b$; $d$ : search cost scaling parameter which determines the difference in search costs across products; $b$ : search cost parameter, which determines the minimum amount of search costs; $k_{i}$ : position of a consumer $i$ with $k_{i} \sim[0 ; 1] ; q_{j}$ : position of product $j$ with $q_{j} \sim[0 ; 1] ; p$ : price of the products; $x_{i, j, t}$ : dummy variable, which is 1 if product $j$ has not yet been purchased by consumer $i$ in observation period $T$; 0 otherwise; $n_{i}, T$ : number of previous purchases of consumer $i$ in the observation period $T$; $f\left(n_{i}, T\right)$ : function which reduces the utility with increasing $n_{i}, T$, here $f\left(n_{i}, T\right)=$ $0.1 * n_{i}, T$; $I$ : index set of consumers;
$J$ : index set of products; $T$ : index set of purchase occasions (= observation period).

Consumers do not buy more than one product per purchase occasion and opt for the product generating the highest utility. Consumers buy as long as there are products that generate a positive utility.

Consumers are simulated by agents who maximize their utility according to the above described model. Thus, we follow the recommendation of Tesfatsion (2002, pp. 55-82) stating that markets can be built up according to the bottomup principle particularly well if the individual behavior can be accurately modeled. The simulation was developed using C\# within the .NET Framework.

In the simulation, we consider the influence of both search and recommendation systems and of hit lists and charts, and thus account for the influence of search costs on sales volume: First, we develop a realistic basic scenario calibrated with actual sales data. Afterwards, we consider four possible scenarios to analyze the impact of sales support systems through changing search costs on demand. Consumers are held constant across all four scenarios by using common random numbers (CRN) (see for example Nelson and Matejcik 1995, pp. 1935-1945), leading to a reduction of variance on scenarios. A total of 50 replications are carried out with each drawing new consumers and products from the above mentioned distributions. The aim of this study is to identify the consequences of the implementation of sales support systems on the demand distribution across products and to break down demand changes in additional consumption and substitution.

\subsection{Calibration of the Simulation}

To calibrate our simulation, we draw on sales data from the leading German video-on-demand provider from December 2004 until August 2007, who may be considered as a quasi-monopolist within that period. In the period under consideration, $1,007,168$ sales could be observed. Since there is no contractual relationship with the consumers, the calculation of the number of active customers is not trivial. We make use of an approach proposed by Reinartz and Kumar (2000, pp. 17-35) which results in a customer number of 15,411 for the given period (about $2 \frac{1}{2}$ years). This means that each customer downloaded about 65 movies in the entire period, i.e. about 24 movies per year. The average assortment size is 789 movies. Thus, 15,411 agents are created, also being uniformly distributed on the Hotelling line and thus having heterogeneous preferences for the offered 789 movies.

The prices of movies in our dataset are on a range of 0.49 EUR to 5.99 EUR. Three out of four prices range between 2.95 EUR and 4 EUR. The average price is 2.91 EUR. Therefore, for the sake of simplicity we assume a price $p=3.00$ EUR for all movies. Based on intensive industry research we assume average costs for one sold movies of 1.30 EUR for the company. This includes both streaming costs (approximately 10\% of the total costs) as well as substantial license costs. Recent movies are usually more expensive than older ones, but license costs only vary by about 5\% according to the industry research. Thus, the profit margin per movie download is 1.70 EUR. Therefore, all purchases generate profit. This means that additional consumption leads to a direct increase in profit for the provider.

To exclusively analyze the influence of different search cost technologies we set the parameters in our model as follows: The utility " $a$ " constitutes 5 EUR for each movie bought and the stochastic component " $z$ " causes fluctuation of the expected benefit by $10 \%$ previous to consumption. After the consumption of the product the random component is removed and the true consumer surplus is calculated. In addition, the utility per consumed movie decreases in a linear manner. In this regard, we assume a decline of 0.10 EUR.

The search costs " $s_{j}$ " for the product " $j$ " are normally distributed on the Hotelling line according to the formula

$$
\begin{aligned}
s_{j} & =\left(1-\frac{\frac{1}{\sigma \cdot \sqrt{2 \pi}} \cdot e^{\frac{\left(q_{j}-\mu\right)}{2 \sigma^{2}}}}{\frac{1}{\sigma \cdot \sqrt{2 \pi}} \cdot e^{\frac{(0,5-\mu)}{2 \sigma^{2}}}}\right) \cdot d+b \\
& =\left(1-e^{\frac{\left(q_{j}-0,5\right)}{2 \sigma^{2}}}\right) \cdot d+b \quad(j \in J)
\end{aligned}
$$


Fig. 6 Distribution of search costs of the movies as located on the Hotelling line
Search costs according to position on Hotelling line

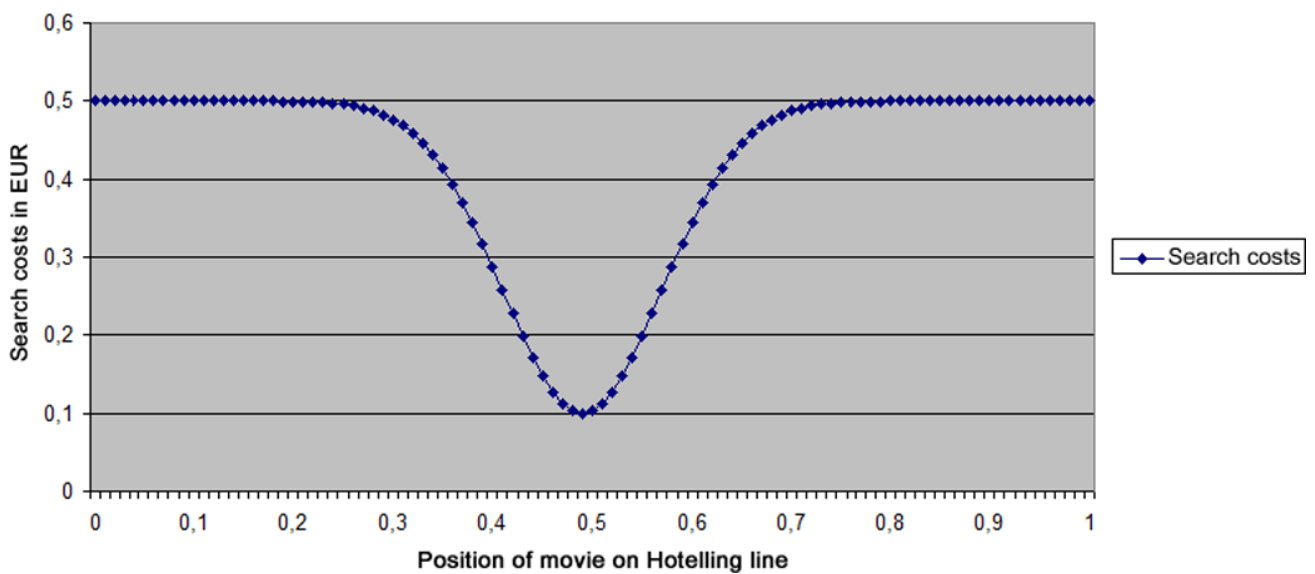

where " $d$ " determines the difference in search costs between niches and blockbusters and " $b$ " yields the minimum height for the search costs. We calibrate our model for a basic scenario: In a first step we calculate sales concentration of the VoD data based on the Pareto principle, which is often referred to as the $80 / 20$ rule. This rule states that only a small proportion of products (top 20\%) generates the majority of the total sales $(80 \%)$. This relationship has first been observed by Pareto in distributions of wealth in societies. In recent decades, this relationship has been found for example in population distributions of cities and also in sales distributions (Brynjolfsson et al. 2007, pp. 17-21). Following the $80 / 20$ rule, often the share of the best selling $20 \%$ of the products in total sales is used as a concentration measure of demand. We follow this approach and determine the share of the most purchased $20 \%$ of the products in total sales. The model's parameters are defined in a way that the concentration of sales according to our model best matches those of the real data. The parameters $d=0.40 \mathrm{EUR}$ and $b=0.10$ EUR are set so that a consumer has to spend about 0.50 EUR finding niche products (products which are located from 0 to about 0.3 and about 0.7 to 1 on the Hotelling line), while they only have to spend 0.10 EUR for searching blockbusters. We derived these values from an experiment on the platform of the VoD provider (see Appendix). The parameters $\mu$ and $\sigma$ are set to $\mu=0.5$ and $\sigma=0.08$ so that around $20 \%$ of the products on the Hotelling line have lower search costs than the remaining movies. Fig. 6 shows the distribution of search costs on the Hotelling line.

Table 2 Summary of scenarios

\begin{tabular}{ll}
\hline Scenario & Description \\
\hline Scenario 1 & All: search costs $-10 \%$ \\
Scenario 2 & Niches can be found more easily: $\sigma+10 \%(=0.088)$ \\
Scenario 3 & Top 100: search costs $-10 \%$ \\
Scenario 4 & Combination of scenario $1-3$ \\
\hline
\end{tabular}

Table 3 Change in the sales concentration across the scenarios

\begin{tabular}{ll}
\hline & Sales concentration \\
\hline Basic scenario & $80.28 \%$ \\
Scenario 1 (search systems) & $76.42 \%^{\mathrm{a}}$ \\
Scenario 2 (recommendation systems) & $77.02 \%^{\mathrm{a}}$ \\
Scenario 3 (hit list etc.) & $82.09 \%^{\mathrm{a}}$ \\
Scenario 4 (combination of $1-3)$ & $79.14 \%^{\mathrm{a}}$ \\
\hline
\end{tabular}

${ }^{\mathrm{a}} p<0.01, N=50$

Subsequently, the search cost are manipulated in comparison to the presented basic scenario as follows:

In scenario 1, we consider the introduction or improvement of search systems (e.g. in the form of search filters). In this case search costs decrease equally across all products by $10 \%$ compared to the basic scenario.

Scenario 2 examines the introduction or improvement of recommendation systems that favor the finding of niche products. Thus, the distribution of Fig. 6 will be more flat, while the absolute level of search costs does not change. To represent this scenario the standard deviation of the normal distribution is increased by $10 \%$ to 0.088 .

Scenario 3 finally describes the introduction or increased use of search technology which particularly supports the sale of blockbusters (e.g. in the form of hit lists). In this scenario, we decrease search costs of the top 100 movies by $10 \%$, while search costs of all other movies remain the same.

In scenario 4 all improvements are introduced simultaneously.

Table 2 summarizes the scenarios.

\subsection{Results}

We first consider the most important figures for the basic scenario. In this case, the $20 \%$ of the best selling products averagely make up $80.28 \%$ of the total sales, which almost exactly corresponds to the Pareto- or 80/20-rule. The validity of the Pareto rule can also be observed in the available sales data.

Table 3 clearly shows that the first two scenarios reduce sales concentration 
measured as the share of top $20 \%$ products in total sales. The results are tested for significance with an ANOVA (pairwise) - all changes are highly significant. The concentration decreases in scenario 1 and 2 so that blockbusters loose in relative importance. This trend has also been observed by Brynjolfsson et al. (2007, pp. 17-21) who found that sales concentration in online sales channels is lower compared to offline sales channels and can be significantly different from the $80 / 20$ rule. The authors show that online the top $27.7 \%$ products are necessary to generate $80 \%$ of total sales, whereas offline the top 20.1\% products contribute $80 \%$ to total sales. Also Oestreicher-Singer and Sundararajan (2006, pp. 5-12) show that sales distributions in the Internet do not follow the $80 / 20$ rule as the top $20 \%$ of the products achieve less than $80 \%$ of total sales. In scenario 3 where search costs for blockbusters are further reduced by hit lists, sales concentration increases significantly and niches relatively loose in importance as expected. Using a combination of different systems, the concentration only marginally changes in scenario 4. The different effects of the search and recommendation systems even out.

In addition to this concentration measure which reflects the relative importance, we also examine the change in consumer surplus, profit, and welfare, which leads to the results illustrated in Table 4 . It becomes clear that all systems increase the company's profits. If one considers only the separate introduction of search technologies in scenario 1 to 3 , it becomes clear that the company would benefit the most from a general reduction in search costs. The introduction of a search system can increase the profit by up to $2.08 \%$. This is not surprising as in scenario 1 the search costs of all products have been reduced, while in scenario 2 and 3 only a part of the overall range of products is affected from the reduction in search costs. The simultaneous introduction of all considered search and recommendation systems increases the profit by $2.80 \%$. Interestingly, the increase in consumer surplus is greater than that of the profit. This means that search technology mainly improves the utility of consumers, which should indirectly lead to higher customer satisfaction and customer loyalty. All results are significant at the $1 \%$ level. The combination of all systems leads to an almost perfectly additive

Table 4 Changes compared to the basic scenario

\begin{tabular}{lccc}
\hline & Profit & Consumer surplus & Welfare \\
\hline Scenario 1 (search systems) & $+2.08 \%^{\mathrm{a}}$ & $+2.54 \%^{\mathrm{a}}$ & $+2.26 \%^{\mathrm{a}}$ \\
Scenario 2 (recommender systems) & $+0.15 \%^{\mathrm{a}}$ & $+0.20 \%^{\mathrm{a}}$ & $+0.17 \%^{\mathrm{a}}$ \\
Scenario 3 (hit list etc.) & $+0.65 \%^{\mathrm{a}}$ & $+1.15 \%^{\mathrm{a}}$ & $+0.85 \%^{\mathrm{a}}$ \\
Scenario 4 (combination of 1-3) & $+2.70 \%^{\mathrm{a}}$ & $+3.66 \%^{\mathrm{a}}$ & $+3.07 \%^{\mathrm{a}}$ \\
\hline
\end{tabular}

${ }^{\mathrm{a}} p<0.01, N=50$

Table 5 Change in sales among the top 20\% products and the rest compared to the basic scenario

\begin{tabular}{llc}
\hline & Top 20\% products & Rest 80\% \\
\hline Scenario 1 (search systems) & $-2.81 \%$ & $+25.04 \%$ \\
Scenario 2 (recommender systems) & $-4.03 \%$ & $+17.42 \%$ \\
Scenario 3 (hit list etc.) & $+2.98 \%$ & $-6.51 \%$ \\
Scenario 4 (combination of 1-3) & $+1.27 \%$ & $+11.38 \%$ \\
\hline
\end{tabular}

Table 6 Decomposition of the effects

\begin{tabular}{lcc}
\hline & Substitution & Additional sales \\
\hline Scenario 1 (search systems), change within rest 80\% & $53.0 \%$ & $47.0 \%$ \\
Scenario 2 (recommendation systems), change within rest 80\% & $95.4 \%$ & $4.6 \%$ \\
Scenario 3 (hit list etc.), change within top 20\% & $59.5 \%$ & $40.5 \%$ \\
\hline
\end{tabular}

gain in utility for all market participants. Interaction effects therefore do not play a role.

Based on the results of the simulation we can also determine the utility in monetary terms that can be achieved through the introduction of improved search technology for the considered VoD provider: based on the sales during the observation period $(>1,000,000)$ a reduction of search costs by $10 \%$ (scenario 1) would generate an additional contribution margin of 29,677.88 EUR for the company. At the same time, consumers would - assuming a willingness to pay of 5 EUR - achieve an additional consumer surplus of 51,164.13 EUR, which can be a strategic competitive advantage for the provider. The company can also use these figures to estimate the maximum of reasonable investments in improved search technology.

Considering the changes in sales in detail, it is striking that both search systems and recommendation systems shift the demand to the niches, thus blockbusters lose in importance in absolute terms. Conversely, hit lists and unpersonalized advertising lead to the fact that sales in the niches decrease and blockbusters gain in importance in absolute terms. The use of all systems increases the sales of both, blockbusters and niche products. Table 5 illustrates this change.

These results already indicate that the decrease in search costs does not only lead to a shift in consumption, but also to additional sales. A decomposition of real additional sales and substitution is useful to be able to make more accurate statements if the margins for blockbusters and niche products are different.

Table 6 shows the results of the decomposition. In the case of scenario 1 , the increased sales volume in the niches results from substitution by $53 \%$, i.e. $53 \%$ of the changed niche sales can be explained by a corresponding decrease in sales of the blockbusters. However, there are also additional sales in the amount of $47 \%$. In scenario 2, an even higher percentage of substitution can be observed. Substitution may well be desirable if the margins are higher in the niches than for the blockbusters. If both margins are equal, the provider can only benefit from the additional sales, which make up nearly $5 \%$ in scenario 2 . In scenario 3 we can 


\section{Abstract}

\section{Oliver Hinz, Jochen Eckert}

\section{The Impact of Search and Recommendation Systems on Sales in Electronic Commerce}

The Internet and related technologies have vastly expanded the variety of products that can be profitably promoted and sold by online retailers. Furthermore, search and recommendation tools reduce consumers' search costs in the Internet and enable them to extend their search from a few easily found best-selling products (blockbusters) to a large number of less frequently selling items (niches). As a result, Long Tail sales distribution patterns emerge that illustrate an increasing demand in niches. We show in this article how different classes of search and recommendation tools affect the distribution of sales across products, total sales, and consumer surplus. We hereby use an agent-based simulation which is calibrated based on real purchase data of a video-on-demand retailer. We find that a decrease in search costs through improved search technology can either shift demand from blockbusters to niches (search filters and recommendation systems) or from niches to blockbusters (charts and top lists). We break down demand changes into substitution and additional consumption and show that search and recommendation technologies can lead to substantial profit increases for retailers. We also illustrate that decreasing search costs through search and recommendation technologies always lead to an increase in consumer surplus, suggesting that retailers can use these technologies as competitive advantage.

Keywords: Long tail phenomenon, Search costs, Search and recommendation systems, Electronic commerce observe that the niche products are replaced by the blockbusters. The additional sales of the blockbusters can be attributed to an appropriate substitution of niches products in $59.5 \%$ of all cases. However, over $40 \%$ of the variation is made up by pure additional sales. This ultimately explains why advertising for blockbusters may be useful. Blockbusters address the preferences of many consumers so that a reduction in search costs leads to significant additional sales. As there are additional sales of blockbusters and niche products in scenario 4 , a decomposition is not possible.

Given our results it can be recommended to the considered companies to first introduce an improved search function, for example by (additional) search filters, and the introduction of a top 100 list. These two features can be implemented very easily and should contribute to an increase in sales. The decision for or against the introduction of a recommendation system must be made in detail. Our results do not consider any differences in margins. If niche products earn a higher profit margin, the introduction of a recommendation system could achieve not only additional profits through additional consumption but also through substitution. According to the results a combination of all systems leads to a nearly additive gain in utility. Positive synergy effects cannot be observed. However, there are also no negative interactions between the systems. This could also explain why Amazon uses a large number of systems simultaneously.

\section{Conclusion and Outlook}

In this paper we first presented several sales support systems and classified them according to their influence on the product-specific search costs. Three categories result: search systems reduce the search costs of all products, while recommendation systems mainly reduce search costs for the niche products. Hit lists and unpersonalized advertising focus on the bestselling products and reduce their search costs. The latter, however, are rather untypical for most of the online providers. Companies often try to particularly stimulate niche demands by search and recommendation systems to serve the heterogeneous preferences of consumers as well as possible.

We presented the effects of various search and recommendation systems on the sales volume and the sales distribution and illustrated the two basic implications of search and recommendation systems: changes in sales may be based on actual additional sales, leading to a rise in sales and in the case of positive margins to a profit increase for the provider. Apart from additional consumption, search and recommendation systems may also trigger substitution effects by only shifting sales and not generating additional demand. In reality we can always observe both consequences for not fully saturated markets, as evidenced by the results of our simulation. Substitution may even have negative consequences on the profit of the provider if high-margin products are substituted by products with lower gross margin. Possibly even positive earning effects of simultaneous additional sales can be overcompensated, resulting in an overall negative effect. Conversely, providers can also take advantage of different margins and support substitution consistently. Sales support systems can thus be an important tool for customer control and profit optimization. If for example the margins are higher in the niches, the company will benefit from the use of recommendation systems not only for direct additional sales, but also for substitution of the blockbusters with niche products.

Furthermore, in addition to a direct increase in profit these systems always lead to a higher consumer surplus, which is often even higher than the increase in profits. For this reason, decreasing search costs can also be a strategic competitive advantage for the company to differentiate itself from its competitors. As the study by Ghose and Gu (2007) shows, Amazon uses this option consistently as Amazon's systems ensure that a customer can find products comparatively faster than with the competitor Barnes \& Noble. The introduction of several search technologies is highly recommended. The results of our study show that largely additive effects on sales, profit, and consumer surplus arise.

The results of our study are not limited to our object of analysis. In particular, the effects of search and recommendation systems on the sales distribution between blockbusters and niches as well as the consumer surplus should also be valid over and above the VoD market. The results regarding the decomposition of the changes in sales into additional consumption and substitution as well as calculated potential profits are dependent 
on the present market demand structure (saturated vs. unsaturated) and should be determined from case to case under consideration of different margins for products.

Particularly interesting for future research projects is the question of whether the effects of search and recommendation systems differ across product categories. Search costs for consumers do not only consist of costs resulting from the actual search effort, but also from processing information based on which users assess the product's quality and its conformity with their preferences (Bakos 1997, p. 1678). The evaluation of experience goods (such as movies, music, or books) is associated to a particularly high level of uncertainty. The quality and consistency of individual preferences can only be determined after the purchase. Just a small number of product characteristics can be assessed objectively (such as e.g. the computing power for PCs) to draw conclusions about the quality and the correspondence to individual preferences (Eliashberg et al. 2000, p. 227). It is therefore likely that search and recommendation systems have particular influence on the sales of experience goods as the relatively high evaluation costs due to high uncertainty prior to purchase can (as a part of search costs) be decreased more than in other product categories, such as hardware, where products are marked by objective and, therefore, objectively assessed properties.

We believe that the potential of sales support systems and the reduction of search costs are not yet fully exploited by all companies. For business and information systems engineering the opportunity arises to develop new algorithms and systems that continuously promote this development to achieve benefits for both, companies and consumers.

\section{References}

Adomavicius G, Tuzhilin A (2005) Toward the next generation of recommender systems: a survey of the state-of-the-srt and possible extensions. IEEE Transactions on Knowledge and Data Engineering 17(6):734-749

Ancarani F (2002) Pricing and the internet: frictionless commerce or pricer's paradise? European Management Journal 20(6):680687

Anderson C (2006) The long tail. Hyperion Press, New York

Ansari A, Essegaier S, Kohli R (2000) Internet recommendation systems. Journal of Marketing Research 37(3):363-375

Arrow KJ (1962) Economic welfare and the allocation of resources for invention. In: Nelson RR (ed) The rate and direction of inventive activity. NBER, New York

Bajari P, Hortacsu A (2003) The winner's curse, reserve prices, and endogenous entry: empirical insights from eBay auctions. RAND Journal of Economics 347(2):329-355

Bakos Y (1997) Reducing buyer search cost: implications for electronic marketplaces. Management Science 43(12):1676-1692

Brynjolfsson E, Hu Y, Smith MD (2000) Frictionless commerce? - An exploratory analysis of Internet pricing behavior. Management Science 46(4):563-585

Brynjolfsson E, Hu Y, Smith MD (2003) Consumer surplus in the digital economy: estimating the value of increased product variety at online booksellers. Management Science 49(11):1580-1596

Brynjolfsson E, Dick A, Smith M (2004) Search and product differentiation at an Internet shopbot. Working paper, Carnegie Mellon University

Brynjolfsson E, Hu Y, Smith MD (2006) From niches to riches: the anatomy of the long tail. Sloan Management Review 47(4):6771

Brynjolfsson E, Hu Y, Simester D (2007) Goodbye pareto principle, hello long tail: the effect of search costs on the concentration of product sales. Working paper, MIT Center for Digital Business

Clay K, Krishnan R, WolffE, Fernandes D (2002) Retail strategies on the web: price and nonprice competition in the online book industry. Journal of Industrial Economics 50:351367

Eliashberg J, Jonker J-J, Sawhney M-S, Wierenga B (2000) MOVIEMOD: an implementable decision-support-system for prerelease market evaluation of motion pictures. Marketing Science 19(3):226-243

Fleder D, Hosanagar K (2009) Blockbuster culture's next rise of fall: the impact of recommender systems on sales diversity. Management Science 55(5):697-712

Ghose A, Gu B (2007) Search costs, demand structure and long tail in electronic markets: theory and evidence. Working paper, Stern School of Business, New York University

Hann IH, Terwiesch C (2003) Measuring the frictional costs of online transactions: the case of a name-your-own-price channel. Management Science 49(11):1563-1579

Häubl G, Trifts V (2000) Consumer decision making in online shopping environments: the effects of interactive decision aids. Marketing Science 19(1):4-21

Hinz O, Hann IH, Spann M (2010) Price discrimination in e-commerce? An examination of dynamic pricing in name-your-ownprice markets. MIS Quarterly (forthcoming)

Hotelling $H$ (1929) Stability in competition. Economic Journal 39(153):41-57

Kamakura W (2009) How Americans and Europeans spend their time. Marketing Seminar Series of the University of Technology in Sydney

Leunga PL, Lau KN (2004) Estimating the cityblock two-dimensional scaling model with simulated annealing. European Journal of Operational Research 158(2):518-524

Nelson BL, Matejcik FJ (1995) Using common random numbers for indifference-zone selection and multiple comparisons in simulation. Management Science 41(12):19351945

Netflix (2009) What is the selection like? http://www.netflix.com/HowltWorks. Accessed 2009-09-28

Oestreicher-Singer G, Sundararajan A (2006) Network structure and the long tail of electronic commerce. Working paper

Pizam A (2005) International encyclopedia of hospitality management. ButterworthHeinemann, Oxford

Reinartz W, Kumar V (2000) On the profitability of long-life customers in a noncontractual setting: an empirical investigation and implications for marketing. Journal of Marketing 64(4):17-35

Resnick P, Varian H (1997) Recommender systems. Communications of the ACM 40(3):56-58

Spann M, Skiera B, Schäfers B (2004) Measuring individual frictional costs and willingness-to-pay via name-your-ownprice mechanisms. Journal of Interactive Marketing 18(4):22-36

Stigler GJ (1961) The economics of information. Journal of Political Economy 69(3):213-225

Tellis GJ (1986) Beyond the many faces of price: an integration of pricing strategies. Journal of Marketing 50(4):146-160

Tesfatsion L (2002) Agent-based computational economics: growing economies from the bottom up. Artificial Life 8(1):5582

Thurstone L (1927) A law of comparative judgement. Psychological Review 34:273286

Varian H (1980) A model of sales. American Economic Review 70(4):651-659

Wu D, Ray G, Geng X, Whinston A (2004) Implications of reduced search costs and free riding in e-commerce. Marketing Science 23(2):255-262 